\title{
The Relationships of Self-regulated Learning and Academic Achievement in University Students
}

\author{
Sanrong Xiao ${ }^{1,}$, Kang $\mathrm{Yao}^{1}$, and Ting Wang ${ }^{2, *}$ \\ ${ }^{1}$ School of Sports and Education, Nanchang University, 330031 NanChang, China \\ ${ }^{2}$ School of Humanities, Jiangxi University of Traditional Chinese Medicine, 330004 NanChang, China
}

\begin{abstract}
Self-regulated learning plays an important role in academic achievement. This paper introduces the relationship between self-regulated learning and academic achievement. Many connections between self-regulated learning and academic achievement have been suggested, such as purposive and goal oriented,incorporating and applying a variety of strategic behaviors. Also it provides some evidences in the mediating effect of academic achievement on the relationship between self-regulated learning and academic achievement. At the end, it questions the existing conclusions and puts forward some researches on main directions where future research should be focused, and the enhancement of previous study.
\end{abstract}

\section{INTRODUCTION}

Self-regulated learning is belonging to the psychology of learning contents.Understanding self-regulated learning is essential in today's academic and social world. We all know that self-regulated learning(SRL) is one of the most investigated topics in education and psychology. While most studies focused on the SRL in primary,middle and high school students,little was known about the SRL in university students ${ }^{[1]}$. Learning is a complex process,one which many students,despite years of schooling,still find mysterious ${ }^{[2]}$. How to distinguish the successful university students from her less successful peers?A growing body of literature supports the notion that optional academic performance is strongly tied to the degree of self-regulation the learner is capable of exercising ${ }^{[3]}$. Understanding the concept of self-regulation is very important in the development of these achievement capabilities for university students. In this study,we analyse the relationships between self-regulated learning and academic achievement in university students.

\section{The relationships of Self-regulated Learning and Academic Achievement}

Zimmerman and Schunk define self-regulated learning in terms of self-generated thoughts,feelings, and actions, which are systematically oriented toward attainment of students' own goals ${ }^{[4]}$. Self-regulated learning is a self-initiated action that involves goal setting and regulating one's efforts to reach the goal, self-monitoring(metacognition), time management, and physical and social environment regulation ${ }^{[5]}$.According to this position, a learner often changes and updates goals and plans while progressing through the task according to the feedback from monitoring, control and reaction processes.That means, self-regulated learners are purposive and goal oriented, incorporating and applying a variety of strategic behaviors designed to optimize their academic performance. While many university students, barring those who are totally tuned out, are, to varying degrees, active in the manner just described,self-regulated learners appear to be both more keenly aware of the relation between specific behaviors and academic success and more likely to systematically and appropriately employ such behaviors ${ }^{[6]}$. Pintrich suggests that the self-regulation consists of four phases.There are forethought, planning and activation; monitoring; control and reaction and reflection. Pintrich also points out that not all academic learning follows these phases because there are many occasions for students to learn academic material in more tacit, implicit or unintentional ways, without self-regulating their learning. Pintrich also adds that the phases are not necessarily hierarchically or linearly structured, but monitoring,control and reaction can be ongoing simultaneously and dynamically. ${ }^{[7]}$

According to Zimmerman's theory, SRL consists of three dynamic and inter-twined phases: forethought, performance or volitional control and self-reflection. The phase of performance or volitional control is similar to the phases in Pintrich's theory: monitoring and control. Based on Pintrich's and Zimmerman's theories, we define SLR, from a social cognitive perspective, as a cyclical and dynamic process which is interdependent of social, environmental and self-influences. ${ }^{\left[{ }^{[-9}\right]}$ Resnick et al think they also exhibit great flexibility in adapting to the variable and sometimes uncertain demands that exist in the classroom, particularly at the university levels. So, the component skills that comprise self-regulated learning need not be viewed as either exotic or as something above and beyond the basics. They are in all likelihood the basic skills that underlie all forms of successful learning ${ }^{[10]}$. Given the degree of success that self-regulated learners have been reported to enjoy, it

" Corresponding author: Ting Wang, E-mail:125323611@qq.com 
follows that understanding the behaviors and processes that underlie self-regulated learning, as well as designing instruction in ways likely to facilitate self-regulation of the learning process. To educational researchers and designers, it is a very important goals. Lindner et al figure out in order to know of the relationship between self-regulated and academic achievement, we can choose five dimensions or working model of self-regulated learning to evaluate this:Metacognition(MCS), Learning Strategies(LSS), Motivation(SES), Contextual Sensitivity(CSS) and Environmental Utilization/Control(ECS) ${ }^{[11]}$.

The self-regulated learner must be able to both internally regulate, monitor, evaluate and modify the learning process, and be alert to and utilize or manage contextual factors such as course and instructor demands, where and when to study, who, when and where to go to assistance etc.Borkowski, Carr et al provided some proofs to test that motivational factors mediate the utilization of both cognitive and environmental resources ${ }^{[12]}$. Karabenick et al think that individuals high in self-efficacy are more likely to use cognitive and metacognitive strategies and to seek appropriate forms of assistance when needed ${ }^{[13]}$. At the same time, there is a positive relationship between a sense of personal control over learning outcomes and subsequent motivation to undertake learning related challenges. In order to find out what extent self-regulated learning plays a significant role in successful academic performance at the university level. Lindner et al chose to do this by employing a self-report inventory, of theirs design, composed of five subscales consistent with those models of self-regulated learning. They enrolled the university students from a mid-western University. The sample contains 160, which consist of 14 graduate students and 2 non-degree students. Linder's results showed that self-regulated learning is an important component in academic success and that it can be measured via a self-report instrument. The results is also indicated that a substantial relationship between self-regulated learning and grade point average. At the same time, that total score showed the highest correlation with performance is in line with the research of Zimmerrman and Martinez-Pons. That is to say that self-regulated learning treated as a single, overarching factor, showed the strongest correlation with achievement. In general, it can be concluded that self-regulated is a significant element in successful university students performance and that many students could profit by forms of instruction that emphasize and promote both the understanding and use of the component skills and attitudes of which self-regulated learning is comprised.It also suggests that the ability to self-regulate the learning process increases with age and academic experience ${ }^{[11][14]}$. Paivi Virtanenand and Nevgi think that disciplinary and gender differences among higher education students in self-regulated learning strategies. In theirs research the samples consisted of 1248, which from eight Finnish universities representing six different disciplines. First, they explored the higher education students' self-regulation in learning and how this differs for female and male students representing the different academic disciplines using self-assessment.The data showed that a stronger positive correlation was found between the intrinsic interest and the other sub-scales of self-regulation in learning than between the utility value and other sub-dimensions. Moreover, intrinsic interest correlated in our data especially strongly with self-assessment, persistency, self-management and time management, which are important elements in SRL. Theirs second research is about the gender differences in self-regulation in learning. The results showed that the female students as compared to the male students were in general slightly higher in the sub-dimensions of SRL, both in the Forethought of Learning and in the Strategies in Learning ${ }^{[9]}$. Sardareh et al figure out this gender difference in self-regulated learning strategies may be due to different factors including: 1) male and female students are different considering personality traits. 2) Although they are at the same level of education, they may have different incentives. 3) Since they are at different educational centers, they may enjoy different instruction and training. 4) They (females) may have received some kind of training or instruction as to the use of SRL strategies ${ }^{[15]}$.

In the other hand, Pintrich and DeGroot et al research has revealed that high achievers reported more use of self-regulated learning strategies than lower achieving students and the assumptions of self-regulated learning offer optimistic implications for teaching and learning. Self-regulation is neither a measure of mental intelligence that is unchangeable after a certain point in life nor a personal characteristic that is genetically based or formed early in life ${ }^{[16]}$.

Alotaibi think that the constructs of self-regulated learning included goal setting and planning, keeping records and monitoring, rehearsal and memorization, and seeking social assistance.And these constructs, especially goal setting and planning, were found to be significant predictors of academic achievement ${ }^{[17]}$.

Students learn self-regulation through experience and self-reflection. Teachers can teach in ways that help students become self-regulating learners ${ }^{[18]}$. Since self-regulation is not a personality trait, students can control their behaviors and affect in order to improve their academic learning and performance. In addition, self-regulated learning is particularly appropriate for college students, as they have great control over their own time schedule, and how they approach their studying and learning.

Wolters and Hussain suggest that college students' tendency to self-regulate their time and study environment, and to avoid unnecessary delays when completing academic tasks is a critical pathway between personal dispositions or traits and students' academic achievement.efforts to promote college students' academic achievement may be more productive if they focus on the motivational and strategic aspects of self-regulated learning ${ }^{[19]}$.

When self-regulated learners find inadequate learning strategies, they regulate their learning activities. Regulating refers to the fine-tuning and continuous adjustment of one's cognitive activities. Regulating activities enhance learning by employing a feedback loop during learning,and self-monitoring training has been found to enhance performance across a wide variety of academic measures. Thus, students can become better learners if they become more aware of 
their learning and then choose to act on that awareness $^{[20]}$.

\section{Discussion and Conclusion}

It is apparent that the role of self-regulated learning is an important factor in the university students learning process. University students are generally assumed to possess metacognitive skills to self-regulate their learning. Furthermore, evidence suggests highly self-regulative learners are academically more successful than those students with low self-regulation skills or those who lack regulation in their learning.

As self-regulated learning is a complex phenomenon. Without a doubt, additional research needs pay more attention to the different dimensions. This study has a number of limitations, many of which are not common to studies based on survey data.More research is also needed in the future on the relations between the students' SRL and the instructional approach adopted, as well as on the connection between self-regulation skills and the students' academic achievement in the different disciplines.

Distinguishing the relationships between self-regulated learning and academic is very important to university students. It also can provide some instructions for policy makers, educators, teachers etc. Because many educators and policy makers currently defend the view that a major goal of formal education should be to teach students self-regulatory skills. These skills are viewed as vital, not only to guide one's own learning during formal schooling, but also to educate oneself and up-date one's knowledge after leaving school. All actors involved in education have raised hopes that psychological knowledge about how students become self-regulated learners and about successful instruction will help us bridge the gap between teaching students disciplinary knowledge and allowing them to acquire strategic knowledge ${ }^{[21]}$.

Curriculum planners should design a curriculum that will encourage students' autonomy in learning. And educators or teachers should try to adopt a student-centered classroom activities and encourage students to be self-regulative in their learning processes by revealing to the students new trends in self-regulated learning. As for students, they should try to improve their self-efficacy beliefs by regularly engaging in highly demanding academic tasks and develop an intrinsic motivation as they approach a new learning task ${ }^{[22]}$.

Fermin and Maria aimed to this field is also point out some of the main directions where future research should be focused ${ }^{[23]}$ :

(1) Improving the definition and making more operational the main processes and activities involved in self-regulated learning, and the differences between this construct and those related to it. For example, self-control, metacognition.

(2) Development of more complete models which incorporate concepts referring to dynamic forces that affect the self-regulation process(e.g.,volitional processes).
(3) Perfecting the research methodology and measuring instruments.

(4) Analysis of the role of learning context in cognition and academic motivation.

(5) Studying the influence of personal human development on the process of self-regulation of learning.

(6) Examining the role of individual and cultural differences in self-regulated learning.

(7) The teaching of different processes which intervene in self-regulated learning within the different areas of the curriculum.It is important to integrate self-regulation activities and strategies within the school context and within the different subjects of the curriculum, and to help students modify them and adapt them to the different learning situations.

\section{Acknowledgements}

This research was financially supported by Jiangxi Provincial planning of social science project(16JY29) and Jiangxi Provincial planning of educational science project(15YB006).

\section{REFERENCES}

1. Wang, J Q, Zhu,Z D, Zhen,S J,M.L, and Zhang,W.A modulating model for the impacting factors in self-regulated learning of college students.Acta Psychological Sinica, vol.42(2), pp.262-270, 2010.

2. Thomas,J.W.andRohwer,W.D.Academicstudying:T he role of learning strategies. Educational Psychologist, vol.21, pp.19-41,1986.

3. Zimmerman,B.J.Self-regulated learning and academic achievement:Anoverview. Educational Psychologyist, vol. 25, pp. 3-17,1990.

4. Zimmerman, B. J and Schunk, D. H. Self-regulated learning and academic achievement:Theory,research,and practice. New York:Springer, pp.4, 1989.

5. Zimmerman, B. J and Risemberg R. Self-regulatory dimensions of academic learning and motivation. In G. D. Phye (Ed.), Handbook of academic learning: Construction of knowledge San Diego, CA: Academic Press, pp.105-125, 1997.

6. Zimmerman, B. J, and Martinez-Pons, M. Development of a structured interview for assessing students use of self-regulated learning strategies. American Educational Research Journal, vol.23, pp.614-628, 1986.

7. Pintrich, P. R. The role of goal orientation in selfregulated learning. In M. Boekaerts, P. R. Pintrich, \& M. Zeidner (Eds.), Handbook of self-regulation San Diego, CA: Academic Press, pp. 451-502, 2000.

8. Zimmerman, B.J. Attaining self-regulation: A social cognitive perspective. In M.Boekaerts, P. Pintrich, \& M. Zeidner (Eds.), Handbook of self-regulation San Diego, CA: Academic Press, pp. 13-39,2000. 
9. Paivi Virtanen and Nevgi. Disciplinary and gender differences among higher education students in self-regulated learning strategies. Educational psychology, vol. 30(2), pp. 323-347, 2010.

10. Resnick, L. B and Klopfer.Toward the thinking curriculum(Ed.), ASCD Publications, 1989.

11. Lindner,Reinhard W., \&Harris B.Self-regulated Learning and Academic Achievement in College Students.San Francisco,CA:AERA, pp.143-150, 1992.

12. Borkowski, J. G, Carr, M, R, E and Pressley, M. Self-regulated cognition:Interdependence of metacogni-tion, attributions, and self-esteem. In, B. F. Jones\&Idol, L(Eds), Dimensions of thingking and cognitive instruction.NJ:Erlbaum,1990.

13. Karabenick, S. A and Knapp, J. R. Relationship of academic help seeking to the use of learning strategies and other instrumental achievement behavior in college students. Journal of Educational Psychology, vol.83(2), pp.221-230,1991

14. Weinsein, C. E, Zimmerman, S. A, and Palmer, D. R. Assessing learning strategies:The design and development of the LASSI. In, C. E. Weinstein, E.T.Goetz,\&P. A. Alexander(Eds). Learning and study strategies:Issues in assessment, instruction, and evaluation. NY: Academic Press, 1988.

15. Sardareh, S. A, Saad, M. R. M, and Boroomand, R. Self-regulated learning strategies (SRLS) and academic achievement in pre-university EFL learners. California Linguistic Notes, vol. 27(1), pp.1-36, 2012.

16. Pintrich, P. R, and DeGroot, E. V. Motivational and self-regulated learning components of classroom academic performance. Journal of Educational Psychology, vol.82(1), pp. 33-40,1990.

17. Alotaibi, K, Riyad,Tohmaz, and Omar, Jabak. The relationship between self-regulated learning and academic achievement for a sample of community college students at king saud university. Education Journal, vlo.6(1), pp.28-37, 2017.

18. Coppola, B. P. Progress in practice:Usingconcepts from motivational and self-regulated learning research to improve chemistry instruction.In P. R. Pintrich (Ed.), Understanding self-regulated learning.San Francisco, CA:Jossey-Bass, pp. 8787-8796, 1995.

19. Wolters, C. A, and Hussain, M. Investigating grit and its relations with college students' self-regulated learning and academic achievement. Metacognition \& Learning, vol.10(3), pp.293-311, 2015.

20. Catherine S, Chen. Self-regulated learning strategies and achievement in an introduction to information systems course. Information Technology,Learning and Performance Journal, vol.20(1), pp.11-13, 2002.

21. Monique Boekaerts. Self-regulated learning: a newconcept embraced by researchers, policy makers,educators, teachers, and students. Learning and Instruction, vol7(2), pp.161-186, 1997.
22. Bakar, N. A, Shuaibu, A, and Bakar, R. A. Correlation of Self-regulated Learning and Academic Achievement among Universiti Sultan Zainal Abidin (UniSZA) Undergraduate Students. International Journal of Academic Research in Business \& Social Sciences, vol.7, pp.254-268, 2017.

23. Fermin. T. M and Maria. C. G. T. Self-regulated learning:current and future directions. Elecrtonic Journal of Research in Educational Psychology, vlo.2(1), pp.1-34, 2004. 